\title{
ARTIGO
}

\section{BARREIRAS ATITUDINAIS SOB A ÓTICA DE ESTUDANTES COM DEFICIÊNCIA NO ENSINO SUPERIOR}

\author{
Attitudinal barriers from the perspective of students with disabilities in higher education
}

Barreras actitudinales desde la perspectiva de estudiantes con deficiencia en la enseñanza superior

Disneylândia Maria Ribeiro

Universidade do Estado do Rio Grande do Norte - Brasil

Alfredo Macedo Gomes

Universidade Federal de Pernambuco - Brasil

\section{Resumo}

O texto tem como objetivo analisar as barreiras atitudinais encontradas por estudantes com deficiência nas interações socioeducacionais com docentes e discentes nos cursos de graduação do Campus Avançado Profa. Maria Elisa de Albuquerque Maia/UERN. A abordagem metodológica adotada é de cunho qualitativo a partir da análise do discurso. A construção dos dados empíricos deu-se por meio dos seguintes procedimentos: visita e levantamento de dados e informações junto à Diretoria de Políticas e Ações Inclusivas da UERN; observações não estruturadas e anotações de campo sobre o cenário e os sujeitos envolvidos na pesquisa; entrevistas semiestruturadas com nove estudantes com deficiência matriculados nos cursos de graduação do referido campus. Os resultados evidenciam que as barreiras atitudinais presentes na interação entre discentes com e sem deficiência expressam as percepções sociais em torno da deficiência, a deficiência associada a déficit, diferença, desvio. $\mathrm{Na}$ relação pedagógica, referidas barreiras se manifestam por meio do pseudotratamento igualitário em sala de aula, no qual se desconsidera as especificidades educacionais dos discentes com deficiência, negando-lhes a adequação de metodologia e recursos didáticos. À guisa de conclusão, sugere que a inclusão educacional no ensino superior depende sobremaneira da adoção de atitudes positivas e da implementação de práticas antidiscriminatórias, de forma a reduzir barreiras na aprendizagem e combater preconceitos.

Palavras-chave: Barreiras atitudinais. Ensino Superior. Estudante com deficiência.

\section{Abstract}

Papers aims to analyse the attitudinal barriers encountered by students with disabilities in the socio-educational interactions with teachers and students in the undergraduation courses of 
the Advanced Campus Profa. Maria Elisa de Albuquerque Maia/UERN. The methodological approach adopted is of a qualitative nature based on discourse analysis. The construction of the empirical data was done through the following procedures: data collection and information in the Policies Unity for Inclusive Actions UERN; unstructured observations and field notes on the scenario and subjects involved in the research; semistructured interviews with nine students with disabilities enrolled in undergraduate courses at the campus. The results show that the attitudinal barriers present in the interaction between students with and without disabilities express social perceptions about disability, deficiency associated with deficit, difference, and deviation. In the pedagogical relationship, these barriers are manifested through egalitarian pseudo-treatment in the classroom, in which the educational specificities of students with disabilities are disregarded, denying them the adequacy of methodology and didactic resources. By way of conclusion, it suggests that educational inclusion in higher education depends heavily on the adoption of positive attitudes and the implementation of anti-discrimination practices, to reduce learning barriers and combat prejudice.

Key-words: Attitudinal barriers. Higher education. Students with disabilities.

\section{Resumen}

El texto tiene como objetivo analizar las barreras actitudinales encontradas por estudiantes con deficiencia y las interacciones socioeducacionales con profesores y alumnos en los cursos de graduación del "Campus Avanzado Profa. Maria Elisa de Albuquerque Maia/UERN". El abordaje metodológico adoptado es de carácter cualitativo a partir del análisis del discurso. La construcción de los datos empíricos se dio por medio de los siguientes procedimientos: visita y levantamiento de datos e informaciones junto a la dirección de Políticas y Acciones Inclusivas de la UERN; observaciones no estructuradas y anotaciones de campo a respecto del escenario y los sujetos involucrados en la investigación; entrevistas semiestructuradas con nueve estudiantes con deficiencia matriculados en los cursos de graduación del referido campus. Los resultados evidencian que las barreras actitudinales presentes en la interacción entre alumnos con y sin deficiencia expresan las percepciones sociales entorno de la deficiencia, la deficiencia asociada al déficit, diferencia, desvío. En la relación pedagógica, referidas barreras se manifiestan por medio del pseudotratamiento igualitario en el aula, en el cual se desconsidera las especificidades educacionales de los alumnos con deficiencia, negándoles la adecuación de metodología y recursos didácticos. A guisa de conclusión, sugiere que la inclusión educacional en la enseñanza superior depende sobremanera de adopción de actitudes positivas y de la implementación de prácticas antidiscriminatorias, de forma a reducir barreras en el aprendizaje y combatir prejuicios.

Palabras-clave: Barreras actitudinales. Enseñanza Superior. Estudiante con deficiencia.

\section{Introdução}

As discussões relativas à diversidade, ao direito à acessibilidade e à inclusão têm se tornado um campo fecundo no contexto educacional e social contemporâneo, fenômeno este que desafia toda a sociedade a pensar uma educação comprometida com os direitos humanos 
fundamentais, capaz de promover condições de acesso e permanência a todos os seus membros.

Sob a égide dos princípios educacionais inclusivos, garantidos e legitimados pelos dispositivos constitucionais e infraconstitucionais no Brasil, a Universidade tem o compromisso social e acadêmico de propiciar acesso mais democrático e de garantir a permanência de todos os estudantes.

A Constituição brasileira (BRASIL, 1988) estabelece que a educação seja garantida a todos, de sorte a que todos possam alcançar os níveis mais elevados da ciência, da tecnologia e das artes, consoante o mérito de cada um. Para a efetivação desse direito, a Carta Maior determina que às pessoas com deficiência será garantido o atendimento educacional especializado, na rede regular de ensino.

A LDB em vigor trata da Educação Especial no Capítulo V, definindo-a como modalidade de ensino oferecida preferencialmente na rede regular de ensino para educandos com deficiência, transtornos globais do desenvolvimento e altas habilidades ou superdotação. De modo que os sistemas de ensino deverão assegurar currículos, métodos, técnicas, recursos educativos e organização específicos, para atender às necessidades e especificidades de aprendizagem da clientela da educação especial. (BRASIL, 1996)

Todavia, a legislação e as normas instituídas não são capazes, por si só, de alterar a realidade educacional. Nesse processo temos que considerar os sujeitos envolvidos, haja vista que eles entendem as políticas públicas de educação de formas distintas, conforme suas vivências, seus interesses e valores culturais. (MICHELS, 2006)

É preciso afirmar, por outro lado, que existem resistências à inclusão, tanto no âmbito escolar, profissional, familiar, como em outros setores da sociedade. As principais resistências têm origem no preconceito, na falta de informação e na intolerância a modelos educacionais mais flexíveis, ou seja, nas barreiras de atitude geradas, nutridas e difundidas no meio social.

As barreiras de atitude são comportamentos e atitudes que dificultam, impedem, “embarreiram” a participação plena, o exercício da cidadania, a inclusão educacional, o empoderamento da pessoa com deficiência. Elas se manifestam no discurso e na dinâmica social e podem se revestir de um caráter assistencialista, paternalista, normalizante, discriminatório, e, por conseguinte, excludente.

As barreiras atitudinais são construções históricas preconcebidas, estereotipadas e generalizadas, que ora subestimam, ora superestimam a capacidade da pessoa com deficiência, traduzindo-se na forma de 
discriminação, intencional ou não [...] tanto podem surgir na linguagem, quanto nas ações e/ou omissões da sociedade diante da pessoa com deficiência. (LIMA; TAVARES, 2012, s/p).

Diante das discussões em tela, objetiva-se, neste estudo, analisar as barreiras atitudinais encontradas por estudantes com deficiência nas interações socioeducacionais com docentes e discentes nos cursos de graduação do CAMEAM/UERN. A partir deste objetivo geral, pretende-se: a) Identificar as formas e as situações em que as barreiras atitudinais se manifestam nas interações socioeducacionais; b) Reconhecer os discursos que geram, tonificam e disseminam as barreiras atitudinais no âmbito acadêmico; c) Compreender como as barreiras de atitude interferem no processo educacional; d) Saber dos discentes com deficiência quais mecanismos utilizam para lidar com as barreiras atitudinais na Universidade.

Realizou-se pesquisa de campo, de abordagem qualitativa (BOGDAN,BIBLEN, 1994; MINAYO, 2000), no Campus Avançado "Prof" Maria Elisa de Albuquerque Maia" (CAMEAM), unidade acadêmica da Universidade do Estado do Rio Grande do Norte (UERN) situada na cidade de Pau dos Ferros, Alto-Oeste Potiguar, uma região que, de forma semelhante a outras regiões brasileiras, tem apresentado, ao largo da história, situações de desigualdade e exclusão social e econômica, resultando no baixo nível de acesso a uma educação pública e gratuita, com qualidade social, ofertada pelas suas redes/sistemas de educação pública.

Os sujeitos da pesquisa são estudantes com deficiência matriculados nos cursos de graduação do CAMEAM, conforme descrito no quadro abaixo. ${ }^{1}$

Quadro 1 - Informações gerais acerca dos sujeitos da pesquisa

\begin{tabular}{|l|l|l|l|l|}
\hline $\mathbf{N}^{\mathbf{0}}$ & NOME & IDADE & CURSO QUE FREQUENTA & \multicolumn{1}{|c|}{ TIPO DE DEFICIÊNCIA } \\
\hline 1 & Igor & 26 & Bacharelado em Administração & Paralisia cerebral \\
\hline 2 & Nara & 53 & $\begin{array}{l}\text { Licenciatura em Música - } \\
\text { PARFOR }\end{array}$ & $\begin{array}{l}\text { Física (encurtamento da perna } \\
\text { direita) }\end{array}$ \\
\hline 3 & Cláudia & 21 & Licenciatura em Educação Física & $\begin{array}{l}\text { Visual (monocular) e fenda } \\
\text { palatina }\end{array}$ \\
\hline 4 & Luan & 26 & $\begin{array}{l}\text { Bacharelado em Ciências } \\
\text { Econômicas }\end{array}$ & Auditiva (perda parcial) \\
\hline 5 & Ugo & 28 & Licenciatura em Geografia & Espectro do autismo \\
\hline 6 & Saulo & 30 & Bacharelado em Administração & $\begin{array}{l}\text { Física (amputação perna } \\
\text { esquerda) }\end{array}$ \\
\hline
\end{tabular}

\footnotetext{
${ }^{1}$ Ressalta-se que os nomes utilizados no decorrer do trabalho são fictícios, dado que essa pesquisa assumiu o compromisso de não divulgar os nomes dos sujeitos mediante assinatura do Termo de Consentimento Livre e Esclarecido, para preservar identidades e histórias pessoais.
} 


\begin{tabular}{|l|l|l|l|l|}
\hline 7 & Ivan & 49 & $\begin{array}{l}\text { Licenciatura em Educação Física } \\
- \text { PARFOR }\end{array}$ & Física (pés tortos congênitos) \\
\hline 8 & Vitor & 40 & $\begin{array}{l}\text { Licenciatura em Música - } \\
\text { PARFOR }\end{array}$ & Visual (cegueira) \\
\hline 9 & Artur & 21 & Licenciatura em Educação Física & Visual (perda da visão periférica) \\
\hline
\end{tabular}

Fonte: Elaboração dos autores a partir do conjunto de informações obtidas na DAIN e nas conversas com coordenadores de cursos, professores e técnicos-administrativos do CAMEAM.

A coleta e geração de dados deu-se por meio dos seguintes procedimentos: a) levantamento documental do marco político-legislativo que trata do direito à educação das pessoas com deficiência; b) visita e levantamento de dados e informações junto à Diretoria de Políticas e Ações Inclusivas da UERN; c) conversas e observações não estruturadas com os segmentos acadêmicos do CAMEAM; d) coleta e geração de dados empíricos através de entrevistas semiestruturadas com discentes com deficiência matriculados nos cursos de graduação do CAMEAM/UERN.

Como aporte metodológico de análise dos dados, adotou-se a abordagem de Análise de Discurso (ORLANDI, 1994, 2001, 2006, 2013) haja vista que as barreiras atitudinais, em geral, surgem, são apresentadas, tonificadas, disseminadas na linguagem, entre os ditos e os não-ditos que constituem o discurso. (TAVARES, 2012). A noção de interdiscurso é essencial à análise das barreiras atitudinais, uma vez que as percepções e representações em torno da deficiência materializadas nos discursos atuais têm sua origem na memória coletiva.

\section{As barreiras atitudinais na interação entre os estudantes com deficiência e os seus pares: o dito e o não-dito}

As relações humanas e os contatos estabelecidos entre os discentes com deficiência e os demais colegas de turma/curso são, em grande medida, reveladores de como ocorre o processo de classificação e diferenciação social de determinado grupo em relação à ou em detrimento de outro. Ter-se-ia, de um lado, grupos rotulados/estigmatizados e, de outro, grupos considerados "normais". Destarte,

Quando normais e estigmatizados realmente se encontram na presença imediata uns dos outros, especialmente quando tentam manter uma conversação, ocorre uma das cenas fundamentais da sociologia, porque, em muitos casos, esses momentos serão aqueles em que ambos os lados enfrentarão diretamente as causas e efeitos do estigma. (GOFFMAN, 2013. p. 23) 
É pertinente sublinhar que, na concepção de Goffman (2013), o termo estigma é utilizado para fazer referência a um atributo profundamente depreciativo; desse modo, o indivíduo estigmatizado é aquele que poderia ter sido facilmente recebido na relação social cotidiana, entretanto, este indivíduo possui um traço que pode impor à atenção e afastar aqueles que ele encontra, destruindo a possibilidade de atenção para outros atributos seus.

Isso ocorre porque, durante a interação, as pessoas tendem a agir e se comportar conforme a representação que se tem da deficiência e da pessoa que a possui. Essa representação é resultante de cognições (conhecimentos, crenças) produzidas por meio de signos e sistemas simbólicos que são veiculados pelo discurso e, por conseguinte, atribuem uma identidade virtual à pessoa com deficiência. A identidade virtual, segundo Goffman (2013), refere-se às exigências e ao caráter que é atribuído ao indivíduo. Esses processos provocam afetos e sentimentos em ambos os envolvidos.

As diferenças que marcam os indivíduos numa determinada sociedade são alvo do estranhamento, pois parte de modelos socialmente dominantes de beleza e normalidade, que colocam determinados indivíduos em situação de vulnerabilidade e exclusão.

Na pesquisa de campo com os discentes do CAMEAM/UERN, foi possível identificar as barreiras atitudinais que permeiam a interação entre os sujeitos da pesquisa e seus pares, no cotidiano acadêmico; observou-se, igualmente, que as atitudes relacionadas aos "colegas" com deficiência se materializam de diferentes formas, como descrito no quadro abaixo:

Quadro 2 - Caracterização da relação entre os discentes com deficiência e seus pares de turma/curso

\begin{tabular}{|l|l|}
\hline CARACTERÍSTICAS & \multicolumn{1}{c|}{ RELATOS ILUSTRATIVOS } \\
\hline Rejeição & $\begin{array}{l}\text { Tem exceções que me tratam com carinho e tem outros que nem falam } \\
\text { comigo, não dizem oi, não dizem nada [...] na hora das apresentações } \\
\text { uns ao invés de prestar atenção no que eu falo, eles ficam conversando } \\
\text { tal, não focam muito, não tão nem aí. (CLÁUDIA) }\end{array}$ \\
\hline Desvalimento & $\begin{array}{l}\text { Você não acredita porque você é uma pessoa cega, o que se passa, no } \\
\text { caso deles comigo é o seguinte "[...] ele é uma pessoa com deficiência } \\
\text { visual então não vai ter o mesmo desenvolvimento do outro" ... há } \\
\text { sempre um olhar preconceituoso relacionado a isso, né? É... eu sentia } \\
\text { isso, mas como eu disse, eu sentia isso logo antes, acho que a gente já } \\
\text { está chegando uma fase mais para o final, então eles já me respeitam } \\
\text { mais. (VITOR) } \\
\text { É assim, todo mundo me trata muito bem, só que assim, às vezes sai... } \\
\text { não crítica, ninguém me criticava no começo e nem criticam hoje no } \\
\text { caso. Só que às vezes as pessoas, tipo escapam alguma coisa, né?! } \\
\text { (LUAN) }\end{array}$ \\
\hline
\end{tabular}




\begin{tabular}{|l|l|}
\hline & $\begin{array}{l}\text { Eu estava aqui na biblioteca aí uma menina chegou tal: } \\
\text { - Você faz o que? } \\
\text { - Educação Física } \\
\text { - E pode desse jeito!? } \\
\text { - Que jeito? Que jeito? } \\
\text { - Você vai ser professora como? Como você vai falar com a turma? Dá } \\
\text { exemplo? (CLÁUDIA) }\end{array}$ \\
\hline Estranhamento & $\begin{array}{l}\text { Tinha deles que ficavam olhando assim, tipo meio acanhado comigo } \\
\text { porque eu tenho certa limitação (IGOR) }\end{array}$ \\
\hline Superproteção & $\begin{array}{l}\text { No começo eram uns 4 ou 5, se apegaram bastante logo comigo. [...] aí } \\
\text { tinha "Fulano", o daqui, ele era muito apegado comigo, onde eu ia ele } \\
\text { estava. [...] Sim, os professores se preocupavam: “Tire a apostila de } \\
\text { Igor”. Aí tinha um colega que dizia: "pode deixar Igor que eu tiro a } \\
\text { sua”. (IGOR) }\end{array}$ \\
\hline $\begin{array}{l}\text { Enaltecimento } \\
\text { potencialidades }\end{array}$ & $\begin{array}{l}\text { [...] os colegas respondiam primeiro que eu: "quem esse aí, faz melhor } \\
\text { que a gente!" (IVAN) }\end{array}$ \\
\hline
\end{tabular}

Fonte: Elaboração da autora com base nas entrevistas realizadas com os discentes.

Esses relatos sinalizam a presença de barreiras atitudinais em relação aos discentes com deficiência: Barreira Atitudinal de Rejeição, Barreira Atitudinal de Menos Valia, Barreira Atitudinal de Superproteção e Barreira Atitudinal de Exaltação do Modelo.

A Barreira Atitudinal de Rejeição é a recusa irracional de interagir com uma pessoa em razão da deficiência. Segundo Tavares (2012, p. 131),

[...] A rejeição não se deve a uma experiência anterior com o indivíduo ou grupo a partir do qual se generaliza uma experiência ruim, ela é a mera expressão da recusa por razão de deficiência, independentemente de quaisquer atributos "positivos" relacionados a uma pessoa ou grupo.

Nesse caso, os indivíduos se negam a interagir com a pessoa com deficiência, como está explícito no relato de Cláudia: “[...] tem outros que nem falam comigo, não dizem oi, não dizem nada [...]". Esse tipo de comportamento leva à segregação e à exclusão social e tem implicações graves no processo educacional da pessoa com deficiência, que experimenta o preconceito em uma de suas formas mais perversas.

A Barreira Atitudinal de Menos Valia apareceu de forma bastante enfática no corpus da pesquisa; diversas situações narradas expressam a avaliação depreciativa que os colegas possuem acerca das potencialidades, ações e produções dos discentes com deficiência. Dessa forma, pode-se pressupor que a pessoa apresentará um desenvolvimento aquém do desejado ou esperado na realização das atividades acadêmicas, o que poderá ter profundas consequências para o exercício futuro da profissão. 
Barreira Atitudinal de Superproteção é a proteção desproporcional esteada na piedade e na percepção da incapacidade do sujeito de fazer algo ou de tomar decisões em função da deficiência (TAVARES, 2012). É o caso da interação descrita por Igor, um ou dois colegas mais próximos o acompanhavam em todas as situações, cercavam-no de atenção e proteção, impedindo que o mesmo realizasse tarefas simples (como ir até a xerox para fazer cópia do material). Essa barreira social impede a conquista da autonomia, da independência e do empoderamento da pessoa com deficiência. (SASSAKI, 2010).

A Barreira Atitudinal de Exaltação do Modelo ocorre quando se compara a pessoa com deficiência e a pessoa sem deficiência, usando a primeira como um modelo a ser seguido; nesse caso, a deficiência é usada para justificar o desempenho da pessoa, a "excepcionalidade" de seus feitos. No âmbito do ensino, essa barreira atitudinal é manifestada quando se utiliza a imagem do estudante com deficiência como modelo de persistência e coragem diante dos demais. (LIMA, TAVARES, 2008).

Ressalta-se que essas atitudes são aprendidas: o preconceito é aprendido na dinâmica social, os discursos que circulam nas mídias, no senso comum, nas ciências e nas artes produzem e fortalecem uma concepção negativa em torno da deficiência e da pessoa que a possui. Assim, conforme Lima e Tavares (2008, p. 1),

As pessoas com deficiência têm, desde sempre, convivido com a confusão entre o que realmente são, pessoas humanas, e o que se pensa que elas são: "deficientes". Corrobora para a perpetuação dessa "confusão" a visão social construída historicamente em torno da deficiência como sinônimo de doença, de dependência, de "indivíduos sem valor", de sofrimento [...] (Grifos no original)

Surgem então os sentimentos de repulsa, medo, dó, admiração. Estes, por sua vez, se materializam em comportamentos de rejeição, avaliação depreciativa, superproteção, exaltação do modelo. As barreiras atitudinais podem estar baseadas em preconceitos explícitos ou a eles dar origem - como a recusa a interagir com a pessoa com deficiência, situação narrada por Cláudia. Entretanto, ações supostamente inocentes sustentam, similarmente, no dia a dia, as barreiras de atitude - como o comportamento do colega de Igor que o superprotege, e os colegas de Ivan que o elogiam exageradamente, comparando seu desempenho com os demais estudantes do Curso.

As questões elencadas até aqui, tanto no âmbito das categorias teóricas quanto nos dados resultantes da pesquisa empírica, levam à conjectura de que existe certa tensão nos contatos sociais estabelecidos entre os sujeitos da pesquisa e os demais estudantes, 
considerando-se que essa interatividade é assentada em barreiras atitudinais diversas, tal como exposto anteriormente.

Essa tensão leva o estudante com deficiência a reagir de diversas formas, na tentativa de se proteger e superar os processos de discriminação e preconceito a que está exposto. Segundo Goffman (2013), o indivíduo estigmatizado pode descobrir que se sente inseguro em relação à maneira como as outras pessoas o identificam. Além disso, é provável que ele sinta que está em "exibição". Diante dessa interação, o indivíduo estigmatizado pode responder antecipadamente através de uma capa defensiva, pode tentar corrigir a sua condição de maneira indireta, por meio de seu esforço pessoal, para superar as adversidades e provar que é capaz, ou então, reagir com agressividade ou retraimento.

Na pesquisa empírica, encontramos dados que apontam para processos de vitimização, encobrimento da deficiência, ênfase no esforço pessoal, dissimulação perceptiva da realidade, tal como sintetizamos no quadro a seguir.

Quadro 3 - Mecanismos utilizados pelos discentes com deficiência para lidar com as barreiras atitudinais na interação com seus pares

\begin{tabular}{|l|l|}
\hline RESPOSTA DEFENSIVA & \multicolumn{1}{|c|}{ RELATOS ILUSTRATIVOS } \\
\hline Vitimização & $\begin{array}{l}\text { [...] eles nunca me colocam nas rodas de conversa, para fazer } \\
\text { trabalho nunca me chamam. } \\
\text { Eu procuro ficar sozinha, no meu canto, recuada, eu não gosto de } \\
\text { me misturar muito não com as pessoas. [...] muitas vezes eu } \\
\text { pensei “vou desistir, né, não é para mim não". (CLÁUDIA) }\end{array}$ \\
\hline Superação (esforço pessoal) & $\begin{array}{l}{[\ldots] \text { quando enfrentei essa faculdade lá em Pau dos Ferros, }} \\
\text { enfrentei com muito objetivo e muito amor porque era um desafio } \\
\text { para mim. (IVAN) }\end{array}$ \\
\hline Encobrimento da deficiência & $\begin{array}{l}\text { Na verdade os que sabiam da minha deficiência me tratavam bem, } \\
\text { me ajudavam, fazia é... eram companheiros comigo, só que eu não } \\
\text { contei pra todo mundo, só a partir do 2 20 período, mas passei } \\
\text { poucos dias depois disso, quando contei pra todo mundo eu saí } \\
\text { [...] É... tipo assim, eu perdi o campo, é a visão periférica. Por } \\
\text { exemplo, se eu chegar dentro da sala, se eu vier de fora da sala e } \\
\text { entrar para dentro, com um lugar pouco iluminado vou sentir } \\
\text { dificuldade, aí tinha vez que um colega discretamente ficava na } \\
\text { frente e me levava até uma cadeira vazia, tipo assim coisa } \\
\text { discreta, eu já tinha combinado com ele. [...] Tive medo de ser } \\
\text { excluso, de ser excluído da turma por causa disso. (ARTUR) }\end{array}$ \\
\hline
\end{tabular}


Dissimulação perceptiva da realidade.
Não, na verdade era coisa da minha cabeça, mas não encontrei [barreiras atitudinais] não. (ARTUR)

Só que não é por mal, ninguém... Eu não entendo por mal, não vi ninguém falar por mal ainda, de mim. (LUAN)

[sobre barreiras atitudinais] Ah, não, sabe que eu nem percebi. (UGO)

Fonte: Elaboração dos autores com base nas entrevistas realizadas com os discentes.

A vitimização é um fenômeno complexo que envolve um processo e um resultado. $\mathrm{O}$ processo é constituído de um conjunto de ações negativas praticadas por um ou mais indivíduos contra outro(s) indivíduo(s), por razões diversas. No caso relatado por Cláudia, nota-se que a discriminação e a rejeição dos colegas a coloca numa situação de vítima, ou seja, ela é alvo do preconceito. Como resultado, ela se vê numa posição de desvantagem, vulnerabilidade e se acomoda no papel de vítima. Sá (2008) apresenta o conceito de vitimização enquanto processo:

[...] ela é um processo, pelo qual alguém (que poderá ser uma pessoa, um grupo, um segmento da sociedade, país) torna-se, ou é eleito a tornar-se um objeto - alvo da violência por parte de outrem (que também poderá ser uma pessoa, grupo, etc.). Como processo, implica uma rede de ações e/ou omissões, interligadas entre si, dotadas de um caráter de historicidade e dinamizadas por interesses, ideologias e motivações conscientes ou inconscientes. (SÁ, 2008, s/p)

A insegurança e o descontentamento estão presentes nessa relação, mesmo que a violência não seja física. $\mathrm{O}$ preconceito carrega em si certo grau de violência simbólica, visto que atenta contra a dignidade da pessoa, lesando sua autoestima. A vitimização revela insegurança, fragilidade emocional, em outras palavras, revela a dificuldade emocional da pessoa em lidar com situações aparentemente embaraçosas.

Diferentemente da postura adotada na situação anterior - vitimização -, há pessoas que procuram "corrigir" suas limitações por meio do esforço pessoal na tentativa de provar para os outros que também é capaz de realizar determinadas tarefas. $\mathrm{O}$ exemplo de superação modifica a percepção que o grupo tem da pessoa com deficiência, nesse caso a deficiência é usada para agregar valor à pessoa pela "perspicácia" de seus feitos. Esta postura está diretamente relacionada à Barreira Atitudinal de Exaltação do Modelo e à Barreira Atitudinal de Adoração do Herói. 
Os outros dois mecanismos de defesa - o encobrimento da deficiência e a dissimulação perceptiva da realidade - identificados na fala dos sujeitos da pesquisa, expressam um comportamento de blindagem, autoproteção psíquica, que ocorre de forma consciente ou não consciente, na tentativa de evitar o incômodo e o embaraço de ser alvo do preconceito. O encobrimento da deficiência, o ocultamento da informação sobre sua deficiência, foi a forma que Artur encontrou para se proteger das barreiras atitudinais percebidas. Esse mecanismo só é possível porque Artur encontrava-se na categoria do “desacreditável”.

Segundo Goffman (2013), o estigmatizado pode ser "desacreditado" ou “desacreditável”. O indivíduo é “desacreditado" quando o seu estigma já é “conhecido" antes mesmo do primeiro contato, ou então, nos casos em que a diferença se torna evidente no momento de sua apresentação pessoal. O “desacreditável” é aquele que a diferença não está imediatamente aparente e não se tem dela um conhecimento prévio.

Artur revelou sua condição apenas para alguns colegas com os quais tinha uma relação de amizade e confiança, preferindo esconder dos demais. Quando questionado a respeito do motivo de tal comportamento, ele responde: "Tive medo de ser excluso, de ser excluído da turma por causa disso". Goffman (2013, p. 86) assevera que a manipulação da informação ocorre "[...] devido às grandes gratificações trazidas pelo fato de ser normal, quase todos que estão numa posição em que o encobrimento é necessário tentaram fazê-lo em alguma ocasião".

O mais intrigante é que Artur decide desistir do curso, no momento em que toda a turma toma conhecimento da sua deficiência, ou seja, quando ele se torna uma pessoa vulnerável a situações sociais e educacionais assentes nos estereótipos e no descrédito.

Sobre a dissimulação perceptiva da realidade, percebe-se no discurso dos discentes uma capa protetora, uma "distorção", uma negação dos processos de preconceito vivenciados. Um não-dizer que escorrega por entre as palavras, constituindo sentidos e significados. O silêncio, o subtendido, o trabalho da ideologia em ação: “[...] na verdade era coisa da minha cabeça" (ARTUR); "Só que não é por mal [...]" (LUAN). O não-dito aponta para diversos questionamentos: O que Artur quis dizer com a afirmação "era coisa da minha cabeça"? Que coisa? Quais situações Luan vivenciou que acredita não terem tido a intenção de o desabonar?

De acordo com Orlandi (2013, p. 48), “[...] nem a linguagem, nem os sentidos, nem os sujeitos são transparentes: eles têm sua materialidade e se constituem em processos em que a língua, a história e a ideologia concorrem conjuntamente". Dessa forma, é preciso pensar as 
condições de produção desses discursos, bem como a posição ocupada pelos sujeitos discursivos - são estudantes universitários em busca de formação acadêmica e profissional. Melhor dizendo, são estudantes universitários que fogem às convenções sociais, que não possuem os atributos, as características físicas e sensoriais socialmente legitimadas como "necessárias" e "adequadas" para estar naquele ambiente.

Os mecanismos utilizados pelos discentes com deficiência, de forma consciente ou inconsciente, para lidar com as barreiras atitudinais, expressam o mal-estar vivenciado no contexto acadêmico, com consequências diversas ao desenvolvimento cognitivo, emocional e social dos estudantes com deficiência.

\section{As barreiras atitudinais no processo pedagógico: à deriva do discurso}

A relação pedagógica estabelecida entre docentes e discentes é decorrente de fatores interpessoais gerados a partir de condicionantes diversos: o conhecimento, o currículo, a relação interpessoal, as atividades didáticas, o espaço, o tempo, o diálogo, o afeto, os conflitos e a disciplina.

O discurso que o docente produz em torno do estudante, especificamente do estudante com deficiência, é preponderante no processo pedagógico, porque as compreensões em torno da deficiência passarão a orientar sua prática e serão muito importantes para a formação humana do estudante e de toda a turma.

Salienta-se que os elementos que levam à determinada ação pedagógica nem sempre estão no nível da consciência do docente. Todavia, são decorrentes de teorias científicas, dos modelos pedagógicos historicamente construídos, dos conhecimentos do senso comum, enfim, dos processos formativos advindos da família, da escola, dos meios de comunicação de massa e da formação ou prática docente.

Nesse estudo, atentou-se para algumas questões específicas do processo pedagógico metodologia empregada e recursos didáticos utilizados pelos docentes nas salas de aula com discentes com deficiência, bem como as dificuldades encontradas pelos discentes na realização de determinadas atividades em virtude das especificidades de suas deficiências. Com isto, buscou-se detectar a presença de barreiras atitudinais, bem como suas implicações no processo educacional do discente com deficiência, a partir dos relatos dos próprios discentes. 
Figura 1 - Discursos que orientam a percepção discente em torno da perspectiva pedagógica adotada pelos docentes

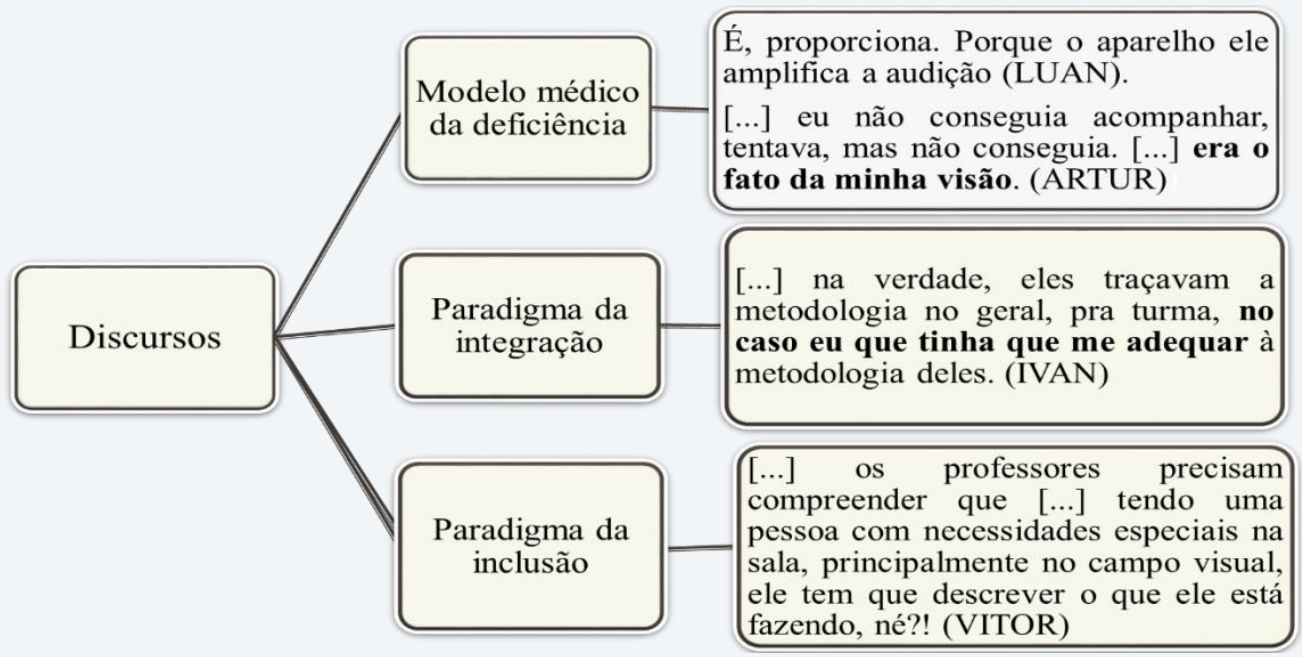

Fonte:

Elaboração dos autores com base nas entrevistas realizadas com os discentes.

Observou-se no corpus das entrevistas que a maior parte dos discentes não tem consciência de que é função do(a) docente adaptar a metodologia conforme as necessidades educacionais decorrentes da deficiência; ao contrário, acham que são eles que precisam adaptar-se à metodologia empregada pelo(a) professor(a). Essa problemática reflete o discurso do paradigma da integração/normalização que vigorou nas políticas educacionais e sociais nas décadas de 70 e 80. De acordo com Sassaki (2010, p. 33-34),

\begin{abstract}
A integração tinha e tem o mérito de inserir a pessoa com deficiência na sociedade, sim, mas desde que ela esteja de alguma forma capacitada a superar as barreiras físicas, programáticas e atitudinais nela existente [...] Sob a ótica dos dias de hoje, a integração constitui um esforço unilateral tão somente da pessoa com deficiência e seus aliados [...] a integração pouco ou nada exige da sociedade em termos de modificação de atitudes, de espaços físicos, de objetos e de práticas sociais.
\end{abstract}

Pois bem, esse discurso foi percebido nos relatos de alguns discentes quando questionados se a metodologia empregada pelos professores proporciona acessibilidade durante as aulas.

Outros discentes acreditam que as dificuldades encontradas no processo de aprendizagem são decorrentes apenas das limitações impostas pela deficiência, e que, dessa forma, não estão relacionadas à falta de acessibilidade pedagógica. Nesse caso, há uma correlação, mesmo que de forma não consciente, no estudante com deficiência, com o modelo médico da deficiência, segundo o qual as deficiências e as limitações são as únicas causas das 
dificuldades de aprendizagem e dos processos de discriminação enfrentados pelas pessoas com deficiência. Contrário ao sentido da inclusão,

O modelo médico parte da premissa implícita de que "quanto mais perto do bom funcionamento estiverem a visão, a audição, o intelecto e o sistema motor de uma pessoa, mais direitos ela vai adquirindo como cidadã". Ainda segundo este modelo, quanto mais comprometido física, intelectual ou sensorialmente for uma criança, um adolescente ou adulto, menos direitos humanos e constitucionais ele ou ela pode ter e exercer. (WERNECK, 2004, p. 1. Grifo no original)

Dos nove (9) discentes pesquisados, apenas um (1) reporta, com plena consciência, a necessidade de adaptação da metodologia empregada pelos professores, e tem a compreensão de que os sistemas educacionais devem se adequar aos diferentes ritmos de aprendizagem, respondendo positivamente às necessidades educacionais das pessoas com deficiência. $\mathrm{O}$ conhecimento em torno das teorias e políticas inclusivas fundamenta as críticas que ele faz em torno das práticas pedagógicas e da falta de tecnologia assistiva no processo de ensino e aprendizagem.

Diante das inferências realizadas, pode-se perceber que há influência de diversos discursos na fala dos discentes, decorrentes dos modelos de percepção da deficiência, bem como dos paradigmas voltados à educação da pessoa com deficiência, construídos em diferentes contextos históricos nos âmbitos científico, político e cultural e que vem coexistindo no âmbito educacional contemporâneo.

É relevante lembrar que esses discursos influenciam, sobremaneira, a forma como os discentes: a) se percebem na dinâmica educacional; b) compreendem o papel pedagógico do professor; c) se constituem enquanto sujeitos da aprendizagem; d) entendem as práticas pedagógicas; e) percebem sua(s) deficiência(s) e especificidades orgânicas e educacionais.

Logo, corrobora-se com a assertiva de Orlandi (2013, p. 60), segundo a qual:

Os sentidos e os sujeitos se constituem em processos em que há transferências, jogos simbólicos dos quais não temos o controle e nos quais o equívoco - o trabalho da ideologia e do inconsciente - estão largamente presentes.

O questionamento sobre possíveis dificuldades na realização das atividades em sala de aula propiciou o surgimento de novos elementos na fala dos discentes que revelam obstáculos provenientes da metodologia utilizada em sala de aula, bem como suas implicações no processo educacional. 
Quadro 4 - Atividades que os discentes com deficiência apresentavam maior dificuldade para realização

\begin{tabular}{|c|c|}
\hline $\begin{array}{c}\text { TIPOS DE } \\
\text { ATIVIDADES }\end{array}$ & RELATOS ILUSTRATIVOS \\
\hline $\begin{array}{l}\text { Seminário/Apresentação de } \\
\text { trabalho }\end{array}$ & $\begin{array}{l}\text { Só seminário, porque tenho que controlar a minha voz [...] começo a } \\
\text { falar e os professores pedem pra mim falar mais alto, aí eu falo: "tá } \\
\text { bom, desculpe professor, é porque não consigo controlar minha voz } \\
\text { porque sou deficiente auditivo". Quando eles não sabem, né? Aí eles } \\
\text { não entendem. [...] o professor mandou falar mais alto. Até uma vez eu } \\
\text { acho que a professora não gostou muito, eu estava apresentando e } \\
\text { depois ela disse que eu falava muito baixo, aí eu disse: "professora é } \\
\text { porque eu tenho deficiência auditiva". Eu acho que ela pegou por mal } \\
\text { alguma coisa. (LUAN) }\end{array}$ \\
\hline Atividades Práticas & $\begin{array}{l}\text { [...] algumas atividades que exigiam mais a parte física, questão de } \\
\text { equilíbrio, por exemplo, às vezes eu ficava de fora, "não professor essa } \\
\text { atividade aí eu não tenho segurança de fazer", então ele dizia: "olhe, } \\
\text { observe, faça até o seu limite", [...] principalmente na metodologia das } \\
\text { danças, lembro muito que tinha algumas aulas de ginástica, aeróbicas } \\
\text { que não dava pra mim. (IVAN) } \\
\text { [...] no campo de regência, no campo da expressão corporal [...] eu digo } \\
\text { que talvez não seja nem uma dificuldade minha, seja mais uma falha } \\
\text { metodológica do professor, o professor deveria fazer as atividades, me } \\
\text { mostrar e me dá um pequeno tempo a mais para que pudesse } \\
\text { desenvolver a atividade junto com a turma fazer. Às vezes eu faço as } \\
\text { atividades, mas em outras situações o tempo passa e eu não consigo } \\
\text { fazer junto com a turma. (VITOR) } \\
\text { A questão que tinha mais dificuldade eram as aulas práticas, só nas } \\
\text { aulas práticas de anatomia [...] A professora de anatomia aplicava } \\
\text { métodos que eu não conseguia acompanhar. [...] ela usava o laser, eu } \\
\text { não conseguia ver o que ela estava mostrando, não conseguia ver o que } \\
\text { ela estava explicando, ela pegava ficava sentada com o lazer mostrando } \\
\text { no quadro, e eu já tinha avisado aos professores do departamento e ela } \\
\text { continuava fazendo isso. (ARTUR) }\end{array}$ \\
\hline
\end{tabular}

Fonte: Elaboração dos autores com base nas entrevistas realizadas com os discentes.

Os dados expostos nos quadros 3 e 4 suscitam a identificação e a interpretação de barreiras atitudinais presentes no processo pedagógico, até mesmo no relato daqueles que haviam declarado, anteriormente, que a metodologia utilizada pelos professores é acessível. A Barreira Atitudinal de Negação, indiscutivelmente, está presente na relação pedagógica descrita pelos discentes com deficiência. Conforme Tavares (2012, p. 132), esse comportamento ocorre "[...] quando se nega a existência ou limite decorrente de uma deficiência. Resulta em um pseudotratamento igualitário que, no entanto, exclui por não considerar os limites reais impostos por uma deficiência”.

A partir do momento em que o professor desconsidera as especificidades de aprendizagem dos discentes no planejamento e na execução de suas aulas, há um processo de 
naturalização da deficiência e negação dos limites decorrentes dela, assim como ocorreu com Artur, Cláudia, Ivan, Luan e Vitor, que não conseguiram acompanhar as aulas e desenvolver as atividades práticas porque a metodologia empregada por seus professores não possibilitava a acessibilidade que eles necessitavam, em função de suas limitações de ordem sensorial e física. De acordo com essa ideia, Carvalho (2014, p. 60) afirma:

Negar a deficiência (sensorial, mental, física, motora, múltipla ou decorrente de transtornos invasivos do desenvolvimento) de inúmeras pessoas é tão perverso quanto lhes negar a possibilidade de acesso, ingresso e permanência bem sucedida no processo educacional escolar [...] É, certamente, uma forma de exclusão, talvez mais grave do que a física - que segrega pessoas em espaços restritivos, pois revela sua exclusão dentro de nós, num movimento inconsciente de rejeição às suas diferenças, porque significativas.

Pode-se também reconhecer, no discurso dos discentes, a Barreira Atitudinal de Ignorância, ou seja, o desconhecimento que se tem de uma determinada deficiência, das potencialidades, das habilidades, da forma própria de aprender, ser e agir da pessoa com deficiência. Esse desconhecimento leva o professor a atitudes de segregação.

Sublinha-se que as barreiras atitudinais tornam a aprendizagem do discente com deficiência limitada e limitante, de baixa qualidade em virtude da restrição de participação do estudante nas diversas atividades realizadas naquele ambiente, pela falta de garantia de equiparação de oportunidades educacionais. As implicações também são emocionais e comportamentais.

A educação inclusiva, de fato, não é uma realidade vivenciada por todos os discentes sujeitos da pesquisa, posto que no meio do caminho, há muitos obstáculos (intrínsecos e extrínsecos a eles) que lhes restringem as possibilidades de desenvolvimento cognitivo, social, educacional e emocional. Em conformidade com Carvalho (2014, p. 121), a mudança de atitude frente à diferença, condição necessária para se repensar o trabalho pedagógico desenvolvido, “[...] é uma barreira de complexa natureza, mais trabalhosa para ser removida, pois se trata de um movimento 'de dentro para fora' e isso leva tempo". Lima e Tavares (2008, p. 11) sustentam que "a inclusão só será concretizada eficientemente quando cada um de nós reconhecer as barreiras que nutrimos e buscar minimizá-las, erradicá-las".

\section{Considerações finais}


A educação inclusiva, aqui compreendida como uma ação social, cultural, política e pedagógica de democratização dos sistemas educativos, se baseia no respeito às diferenças e no direito de todos os estudantes de participarem, de pertencerem ao grupo e de aprenderem juntos, sem nenhum tipo de segregação ou discriminação. Por isso, as políticas de educação inclusiva apresentam-se como campo de discussão demasiadamente pertinente no contexto da educação superior, tendo em vista que esse nível de ensino tem se tornado mais acessível e a formação universitária tem se constituído um elemento essencial para o desenvolvimento pessoal e profissional dos indivíduos.

São muitos os aspectos que dificultam a inclusão satisfatória do estudante com deficiência no ensino superior. Na gênese desse processo, encontram-se as barreiras atitudinais que, de forma ambígua e muitas vezes não consciente, permeiam as ações e políticas educacionais.

Tais barreiras são veiculadas e tonificadas pela linguagem, na confluência dos discursos - médico, psicológico, pedagógico, dentre outras formas de organização do saber que constroem as categorias classificatórias - "o normal”, “o anormal”, "o sã”, o "não sã”, “o belo", "o feio", "o deficiente", "o educável” - gerando discursos, afetos e disposições negativas relacionadas à pessoa com deficiência.

No contexto investigado nota-se que as barreiras de atitude estão presentes na interações socioeducacioanais e expressam as percepções sociais em torno da deficiência - a deficiência associada a déficit, diferença, desvio; logo a pessoa torna-se desacreditada, passando a ser tratada como tal.

$\mathrm{Na}$ relação pedagógica elas se manifestam por meio do pseudotratamento igualitário em sala de aula, no qual se desconsidera as especificidades educacionais dos discentes com deficiência, negando-lhes a adequação de metodologia e recursos didáticos.

Destarte, a inclusão de pessoas com deficiência no ensino superior envolve a adoção de atitudes positivas, a criação de culturas inclusivas e a implementação/mobilização de práticas democráticas e antidiscriminatórias, de forma a reduzir barreiras na aprendizagem, combater preconceitos e a exclusão educacional, problematizando os processos de produção das diferenças no interior de cada instituição. Assim, é papel da Universidade congregar ações no ensino, na pesquisa e na extensão. Assim, destaca-se a formação de profissionais especializados, a produção do conhecimento científico na área das deficiências e a disseminação de propostas educativas de orientação inclusiva. 
Defende-se, desse modo, a importância de um trabalho responsivo com a construção de uma cultura dos direitos humanos em todos os espaços sociais, e a universidade tem papel fundamental no processo de formação de uma consciência voltada ao respeito à diferença e à diversidade, pois a universidade é espaço onde as diferenças se encontram, as culturas se cruzam e a aprendizagem dos processos de emancipação e formação cidadã se concretizam.

\section{Referências}

BOGDAN, Roberto; BIKLEN, Sari Knopp. Investigação Qualitativa em Educação. Porto. Porto Editora. LDA. 1994

BRASIL, República Federativa. Constituição Federal de 1988. Disponível em http://www.planalto.gov.br/ccivil_03/constituicao/constituicaocompilado.htm. Acesso em 10 de fev. de 2015.

BRASIL. Ministério da Educação. Lei n 9394, de 20 de dezembro de 1996. Diretrizes e Bases da Educação Brasileira, Brasília, 1996.

CARVALHO, Rosita Edler. Educação inclusiva: com os pingos nos "is". 10 ed. Porto Alegre: Mediação, 2014.

GOFFMAN, Erving. Estigma: Notas sobre a manipulação da identidade deteriorada. 4 ed. Rio de Janeiro: LTC, 2013.

LIMA, Francisco José de; TAVARES, Fabiana S. S. Barreiras atitudinais: obstáculos à pessoa com deficiência na escola. In SOUZA, Olga Solange Herval (org.). Itinerários da Inclusão Escolar: múltiplos olhares, saberes e práticas. Porto Alegre: AGE, 2008.

LIMA, Francisco José de; TAVARES, Fabiana S. S. Conceituação e taxonomia das barreiras atitudinais praticadas contra a pessoa com deficiência. 2012. Disponível em http://www.deficienteciente.com.br/2012/09/barreiras-atitudinais-obstaculos-a-pessoa-comdeficiencia-na-escola.html Acesso em 10 jul. de 2014.

MICHELS, Maria Helena. Gestão, formação docente e inclusão: eixos da reforma educacional brasileira que atribuem contornos à organização escolar. Revista Brasileira de Educação. Rio de Janeiro, v. 11, n. 33 set./dez. 2006. Disponível em: http://www.scielo.br/pdf/rbedu/v11n33/a03v1133.pdf. Acesso em: 20 de maio 2015.

MINAYO, Maria Cecília de Souza. Fase de trabalho de campo. In: Desafio do Conhecimento. Pesquisa Qualitativa em Saúde. 7. Ed. São Paulo: HUCITEC; Rio de Janeiro: Abrasco, 2000. [p.106 -133].

ORLANDI, Eni Pucinelli. Discurso, Imaginário Social e Conhecimento. Em Aberto, Brasília, ano 14, n. 61, jan/mar. 1994.

ORLANDI, Eni Pucinelli. Discurso e leitura. 6 ed. São Paulo: Cortez, 2001. 
ORLANDI, Eni Pucinelli. Análise de Discurso: Princípios e Procedimentos. 11 ed. Campinas, SP: Pontes, 2013

ORLANDI, Eni Pucinelli. A linguagem e seu funcionamento: As formas do discurso. 4 ed. Campinas, SP: Pontes, 2006.

SÁ, Alvino Augusto de. Algumas considerações psicológicas sobre a vítima e a vitimização. 2008. Disponível em http://www.leliobragacalhau.com.br/algumasconsideracoes-psicologicas-sobre-a-vitima-e-a-vitimizacao/. Acesso em: 24 de nov. 2015

SASSAKI, Romeu Kasumi. Inclusão: Construindo uma sociedade para todos. 8 ed. Rio de Janeiro: WVA, 2010.

TAVARES, Fabiana S.S. Educação Não Inclusiva: a trajetória das barreiras atitudinais nas dissertações de educação do Programa de Pós-graduação em Educação (PPGE/UFPE). Recife, UFPE, 2012. 595f. Dissertação de Mestrado apresentada ao Programa de Pós-Graduação em Educação da Universidade Federal de Pernambuco, Recife, 2012.

WERNECK, Cláudia. Modelo médico x Modelo social da deficiência: Manual da mídia legal 3: comunicadores pela saúde / Escola de Gente - Rio de Janeiro: WVA Editora, 2004.

Ms. Disneylândia Maria Ribeiro Universidade do Estado do Rio Grande do Norte - Brasil

Núcleo de Estudos em Educação - NEEd

E-mail: d-landia@hotmail.com

Dr. Alfredo Macedo Gomes Universidade Federal de Pernambuco - Brasil Centro de Educação.

Programa de Pós-Graduação em Educação (PPGE). Grupo de Pesquisa Laboratório de Pesquisa em Políticas Públicas, Educação e Sociedade

Bolsista em Produtividade CNPq. E-mail: alfredomgomes@gmail.com

Recebido em: 12 de novembro de 2016 Aprovado em: 02 de dezembro de 2016 